\title{
The invisible hands conducting minimally invasive mitral valve surgery
}

\author{
Jason J. Han, MD, and Pavan Atluri, MD
}

\footnotetext{
From the Division of Cardiovascular Surgery, Department of Surgery, University of Pennsylvania, Philadelphia, $\mathrm{Pa}$.

Disclosures: Authors have nothing to disclose with regard to commercial support.

Received for publication April 11, 2018; accepted for publication April 11, 2018; available ahead of print May 10 , 2018.

Address for reprints: Pavan Atluri, MD, Division of Cardiovascular Surgery, Hospital of the University of Pennsylvania, 3400 Spruce St, 6 Silverstein Pavilion, Philadelphia, PA 19072 (E-mail: Pavan.Atluri@uphs.upenn. edu).

J Thorac Cardiovasc Surg 2018;156:617-8

$0022-5223 / \$ 36.00$

Copyright (C) 2018 by The American Association for Thoracic Surgery

https://doi.org/10.1016/j.jtcvs.2018.04.054
}

As technology and our understanding of the human body continue to improve, there is a natural progression in surgery toward achieving more while doing less. So, too, in the field of mitral valve surgery, such enthusiasm for lessinvasive approaches has been increasingly espoused by patients and referring physicians alike during the past several decades. Yet, as Hawkins and colleagues ${ }^{1}$ astutely note in this issue of the Journal, the adoption of minimally invasive mitral valve surgery (mini-MVR) has been relatively stagnant, recently comprising only $20 \%$ of all mitral operations at only a quarter of the cardiac surgery centers in the United States. Because mini-MVR has been firmly established as a noninferior option to traditional, open mitral valve replacement (MVR), this standstill beckons the question of where the barriers to entry and shift in paradigm exist.

This article by Hawkins and colleagues ${ }^{1}$ is a timely contribution to our understanding of this topic, rendering it more nuanced and multifactorial. In addition to reinforcing the abundant literature on the excellent outcomes able to be accomplished with mini-MVR, Hawkins and colleagues ${ }^{1}$ found no financial impediment to its widespread adoption in a successfully propensity-matched analysis. Despite longer operative times associated with mini-MVR, which translates to marginally higher operative costs, there was no significant difference in overall cost relative to conventional MVR, likely because of reduced ventilator dependence, transfusion, and ancillary costs. The major strength of this analysis is its propensity matching, which reduces the treatment allocation bias inherent in retrospective analysis, particularly in this area, in which patients undergoing conventional MVR tend to be markedly sicker with more varied mitral disease etiologies. The composition of repair versus replacement, and inclusion of concomitant operations such as tricuspid valve repair and ablation, can also skew findings without matching. Only a few studies to date have addressed both clinical and economic advantages of mini-MVR with this degree of statistical rigor. ${ }^{2-4}$ and satisfaction.

\section{References}

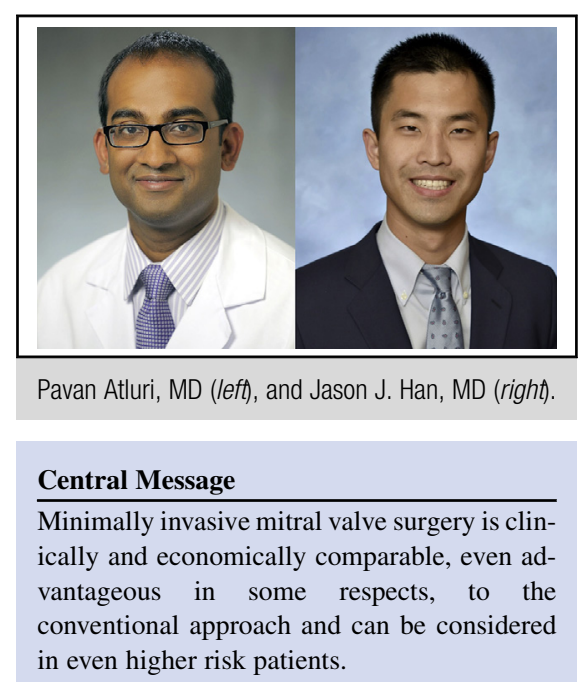

See Article page 611

Interestingly, Hawkins and colleagues ${ }^{1}$ did not find that mini-MVR reduced length of stay or the rates of readmission and discharge to facility, which one would expect to have major implications for resource use and has been a recurrent finding in other studies.

Of note, although Hawkins and colleagues ${ }^{1}$ found excellent clinical outcomes and resource use in mini-MVR, the degree of generalizability outside a specialized, academic setting remains to be further elucidated. In part, operating with high-volume surgeons and staff well-versed in miniMVR may have enabled such degree of success, even among higher risk patients. We have reported similar findings at our institution previously, ${ }^{5,6}$ although our aortic occlusion technique of choice was an endoaortic balloon through femoral cannulation instead of a direct clamp, which admittedly has additive cost.

Overall, Hawkins and colleagues ${ }^{1}$ deserve our congratulations on their rigorous analysis and excellent presentation. In an era where the implications of rapidly emerging transcatheter therapies for mitral valve diseases are profound, these studies are crucially needed to continue to help define and steer us toward the path of improved patient outcomes

1. Hawkins RB, Mehaffey JH, Kessel SM, Dahl JJ, Kron IL, Kern JA, et al. Minimally invasive mitral valve surgery associated with excellent resource utilization, cost, and outcomes. J Thorac Cardiovasc Surg. 2018;156:611-6. 
2. Iribarne A, Easterwood R, Russo MJ, Wang YC, Yang J, Hong KN, et al. A minimally invasive approach is more cost-effective than a traditional sternotomy approach for mitral valve surgery. J Thorac Cardiovasc Surg. 2011;142: 1507-14.

3. Grossi EA, Goldman S, Wolfe JA, Mehall J, Smith JM, Ailawadi G, et al; Economic Workgroup on Valvular Surgery. Minithoracotomy for mitral valve repair improves inpatient and postdischarge economic savings. J Thorac Cardiovasc Surg. 2014;148:2818-22.e1-3.

4. Svensson LG, Atik FA, Cosgrove DM, Blackstone EH, Rajeswaran J, Krishnaswamy G, et al. Minimally invasive versus conventional mitral valve surgery: a propensity-matched comparison. J Thorac Cardiovasc Surg. 2010; 139:926-32. e1-2.

5. Atluri P, Stetson RL, Hung G, Gaffey AC, Szeto WY, Acker MA, et al. Minimally invasive mitral valve surgery is associated with equivalent cost and shorter hospital stay when compared with traditional sternotomy. J Thorac Cardiovasc Surg. 2016; 151:385-8.

6. Goldstone AB, Atluri P, Szeto WY, Trubelja A, Howard JL, MacArthur JW Jr, et al. Minimally invasive approach provides at least equivalent results for surgical correction of mitral regurgitation: a propensity-matched comparison. J Thorac Cardiovasc Surg. 2013;145:748-56. 